\title{
Effect of Rate of Freezing on Degree of Segregation in Alloys
}

\author{
by William $T$. Olsen, Jr. and Ralph Hultgren
}

W HEN a liquid alloy freezes, the solid first formed usually difrers widely in chemical composition from that last formed, so that there is segregation in the alloy as cast. For example in the copper-nickel system (fig. 1) the first solid formed from a liquid containing 55 atomic pet $\mathrm{Cu}$ may contain as little as 38 pct $\mathrm{Cu}$, while the last must contain well over 55 pet.

Three factors may act to decrease segregation from the maximum possible.

1. Diffusion in the cooling solid tends to make the phase homogeneous, decreasing segregation. This may be important at slow rates of cooling.

2. Segregation is impossible without diffusion in the liquid. At extremely rapid rates of cooling there may not be enough time to allow maximum segregation.

3 . Supercooling delays nucleation to temperatures well below the liquidus thereby decreasing segregation. Hence the first nucleus in the coppernickel system may contain well over 38 pct $\mathrm{Cu}$. At sufficient supercooling the first nucleus may form below the solidus, in which case there is no reason to expect any segregation whatever.

From these considerations, we could predict that at sufficiently low rates of cooling the alloy would be unsegregated because of factor 1 and at sufficiently high rates of cooling there should also be no segregation because of factors 2 and 3 . Considerable segregation should occur only at intermediate rates of cooling.

We have demonstrated experimentally that segregation can be completely suppressed by rapid rates of cooling. For the alloys studied, however, these rates are too great to be attained in any commercial practice.

An alloy of 55 atomic pet $\mathrm{Cu}, 45$ atomic pet $\mathrm{Ni}$ was frozen by cooling at varying rates. The degree of segregation in the solid was determined by X-ray diffraction photographs. Slow rates were obtained by slowly cooling the furnace containing the liquid alloy; fast rates by pouring or ejecting droplets of the alloy into water or iced sodium hydroxide solutions. The cooling rate of the droplets can be calculated from their dimensions by assuming reason-

${ }^{1}$ Niels Engel: Untersuchungen Uber die Stahlhartung. Ingenorvidenskabelige Skrifter A Nr. 31 Copenhagen. 1931.

Table I. Effect of Rate of Cooling on Segregation

\begin{tabular}{|c|c|c|c|c|c|}
\hline \multicolumn{3}{|c|}{$\begin{array}{c}\text { Composition of Alloy, } \\
\text { Atomic Pet } \\
\end{array}$} & \multirow{2}{*}{$\begin{array}{c}\text { Rate of } \\
\text { Cooling, } \\
\text { Deg C per sec }\end{array}$} & \multicolumn{2}{|c|}{$\begin{array}{c}\text { Composition } \\
\text { Range, } \\
\text { A tomic Pct } \mathrm{Cu}\end{array}$} \\
\hline $\mathbf{C u}$ & $\mathbf{N i}$ & $\mathbf{A u}$ & & $\begin{array}{l}\text { First to } \\
\text { Freeze }\end{array}$ & $\begin{array}{l}\text { Last to } \\
\text { Freeze }\end{array}$ \\
\hline 55 & 45 & & $\begin{array}{c}0.0055 \\
5,700 \\
13,300 \\
\mathbf{9 7 , 0 0 0}\end{array}$ & $\begin{array}{l}38 \\
44 \\
46.5 \\
55\end{array}$ & $\begin{array}{l}59.5 \\
59.5 \\
59.5 \\
55\end{array}$ \\
\hline 16.5 & & 83.5 & $\begin{array}{c}\quad 0.0055 \\
4,325 \\
11,100 \\
61,600 \\
\end{array}$ & $\begin{array}{l}16 \\
15 \\
13 \\
16.5\end{array}$ & $\begin{array}{l}18.5 \\
18.5 \\
18.5 \\
16.5\end{array}$ \\
\hline
\end{tabular}

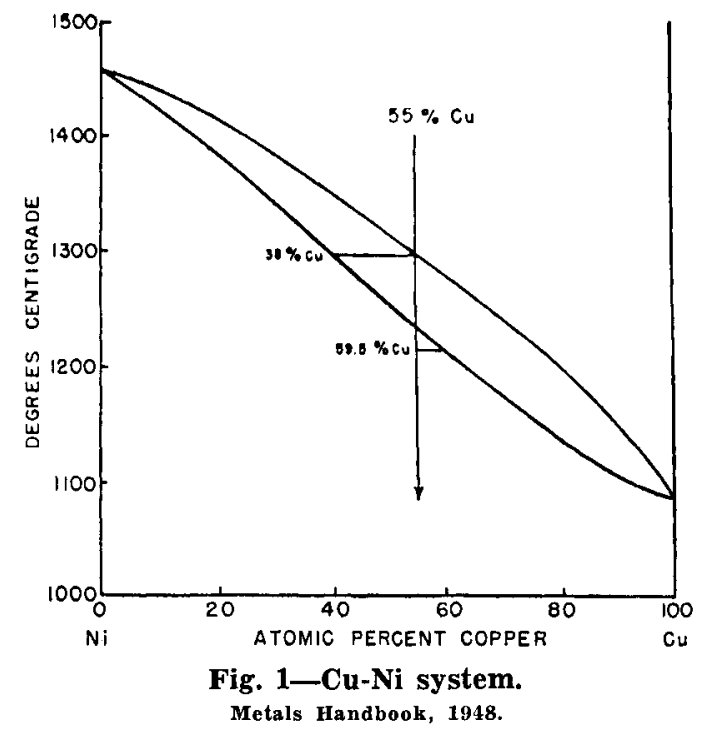

able values of thermal conductivity. ${ }^{1}$ The experiments were repeated with an alloy of 16.5 pct $\mathrm{Cu}$ and 83.5 pet Au. A single experiment also showed a 50 atomic pet $\mathrm{Bi}-\mathrm{Sb}$ alloy had no segregation at the most rapid quench.

The position of back-reflection X-ray diffraction lines is a highly sensitive function of the lattice constant, which in turn depends on the chemical composition of the phase. A phase of varying composition will give broad diffraction lines. By measuring the edges of these lines and making suitable corrections for intrinsic line width, it is possible to determine the range of lattice constants represented. These can be converted to chemical compositions from a lattice constant vs. composition curve. Results are shown in table I.

In the copper-nickel system the greatest segregation is found at the slowest cooling rates, where the lowest percentage of copper theoretically possible is found. In the copper-gold system, on the other hand, the degree of segregation is decidedly less at the slowest rates of cooling, being greatest at $11,100^{\circ} \mathrm{C}$ per sec. At no rate is the theoretically lowest percentage of copper (12 pct) found.

At the rates of cooling found in sand and die castings the degree of segregation is large and depends little on the rate of cooling.

\section{Acknowledgment}

Most of the material in this paper is abstracted from a thesis presented by William T. Olsen, Jr. in 1948 in partial fulfillment of the requirements for the degree of Master of Science at the University of California.

W. T. OLSEN, JR., University of California, Berkeley, Calif., and R. HULTGREN, Member AIME, is Professor of Metallurgy, University of California.

TN 48 E. Manuscript received Sept. 12, 1950. 